\title{
THE YARLUNG ZANGBO RIVER EXTRACTION AND CHANGE DETECTION BASED ON LANDSAT SERIES
}

\author{
Y. J. Cao, G. Qiao* \\ College of Surveying and Geo-Informatics, Tongji University, Siping Road 1239, Shanghai, China - yogacao@tongji.edu.cn, \\ qiaogang@tongji.edu.cn
}

Commission III, WG III/9

KEY WORDS: Landsat, River Extraction, Object-oriented Classification, Change analysis

\begin{abstract}
:
Yarlung Zangbo River is one of the most important rivers in the southwest river source area, it is the longest plateau river in China, the cradle of the birth and development of Tibet civilization, and also an international water system. It is of great significance to study its water resources utilization and water environment protection. This paper compared different river extraction methods, including the normalized difference water index, multi-band spectral correlation threshold method, maximum likelihood classification method and object-oriented classification method, based on Landsat images, and combined with remote sensing and GIS technologies. The study area is Yarlung Zangbo River, one of the main rivers in southwest river source region. Meanwhile, river changes have been analysed based on upstream and midstream of Yarlung Zangbo River extracting results of four images in different periods. The result shows that object-oriented classification method has advantage of removing mountain shadow, its accuracy of river extraction is the highest, and Yarlung Zangbo River area shows a decreasing trend from 2000 to 2016, and there are some changes of watercourse in midstream as well.
\end{abstract}

\section{INTRODUCTION}

The southwest river source area is the most abundant area of water resources and hydropower resources in China. It is also the birthplace of the major rivers in Southeast Asia, and has important strategic position. Yarlung Zangbo River is one of the most important rivers in the southwest river source area, it is the longest plateau river in China, the cradle of the birth and development of Tibet civilization, and also an international water system. It is of great significance to study its water resources utilization and water environment protection. However, due to the remote location and complex terrain of the southwest river source area, the observation of the surface hydrological meteorological elements is extremely lacking, which seriously hinders the study of water resources and the understanding of water cycle.

Remote sensing is a kind of comprehensive observation technology developed in the $1960 \mathrm{~s}$, has a wide range of detection, fast data collection, dynamic reflection of changes. Therefore, the use of satellite remote sensing images to extract river information has obvious advantages in the southwest river source area, which has special climate and terrain conditions, and can make a three-dimensional and comprehensive observation of the water resources.

In this paper, take upstream and midstream of Yarlung Zangbo River for example, studying the best approach for river extraction through the comparative analysis of various river extraction methods, and then analysing the change of river, to provide the theoretical basis for the adaptability of water resources in Yarlung Zangbo River.

\section{REMOTE SENSING DATA AND DATA PREPROCESSING}

\subsection{Remote Sensing Data}

The data includes Landsat7 ETM + and Landsat8 OLI images. The receiving time and scene number of each image are shown in Table 1, and the location of study area is shown in Figure 1.

\begin{tabular}{|c|c|c|c|}
\hline Data Source & Row & Column & Receiving Time \\
\hline ETM+ & 137 & 40 & $2000-12-28$ \\
ETM+ & 142 & 39 & $2002-01-03$ \\
OLI & 137 & 40 & $2015-12-30$ \\
OLI & 142 & 39 & $2016-01-02$ \\
\hline
\end{tabular}

Table 1. Receiving time of remote sensing data and its scene number

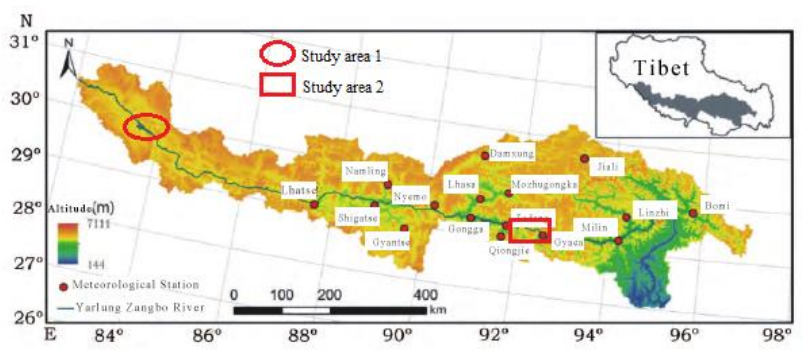

Figure 1. Location of study area in Yarlung Zangbo River (Modified from (Lv, 2014)) 


\subsection{Data Preprocessing}

First of all, this paper used histogram minimum method to do radiometric correction, which enhance the image contrast, improve the image brightness, and basically eliminate the influence of atmospheric radiation. Then we cut the image to reduce the amount of data, speed up the processing and eliminate some irrelevant information which might affect river extraction accuracy. And in order to extract the river afterwards, we carried out the false colour synthesis of the images. After preprocessing, the false colour composite images were shown in Figure 2 and Figure 3.

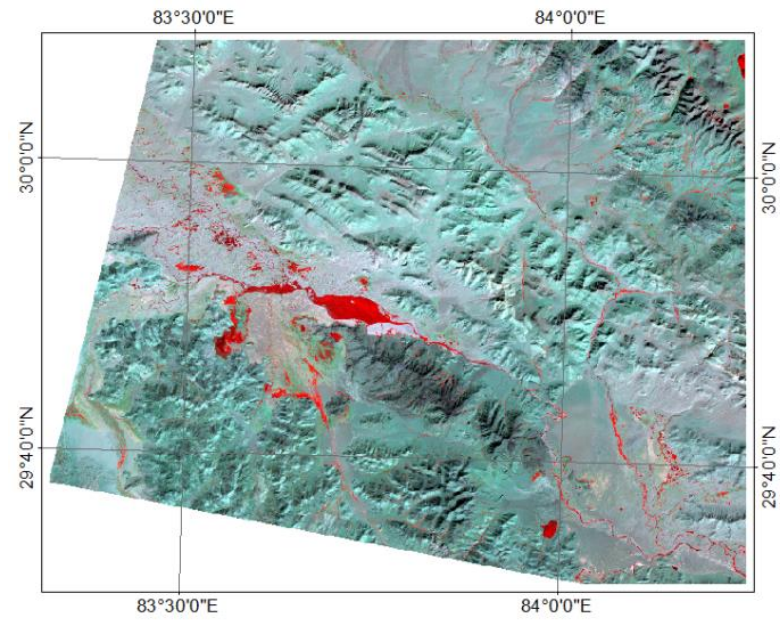

Figure 2. False colour composite image of upstream after

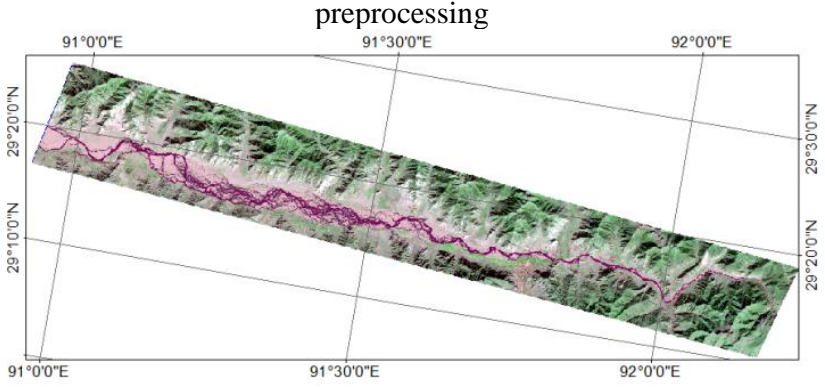

Figure 3. False colour composite image of midstream after preprocessing

\section{RIVER EXTRACTION METHODS}

The study of river extraction methods in this section takes Landsat7 ETM+ images of the midstream of Yarlung Zangbo River in 2000 as an example.

\subsection{Normalized Difference Water Index (NDWI)}

Inspired by NDVI, NDWI (McFeeters, 1996) was put forward in 1996. The expression is as follows:

$$
N D W I=\frac{G R E E N-N I R}{G R E E N+N I R}
$$

where GREEN is a band that encompasses reflected green light and NIR represents reflected near-infrared radiation.

When equation (1) is used to process a multispectral satellite image that contains a reflected visible green band and an NIR band, water features have positive values; while soil and terrestrial vegetation features have zero or negative values, owing to their typically higher reflectance of NIR than green light. This effectively eliminates the terrestrial vegetation and soil information and retains the open water information for analysis. The result of river extraction using NDWI is shown in Figure 4.

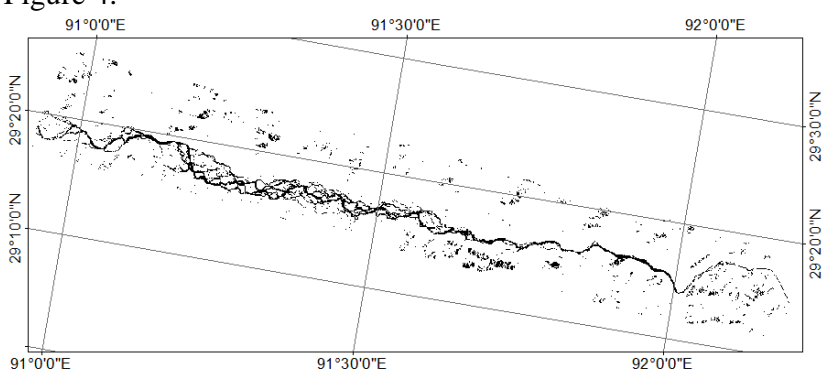

Figure 4. River extraction result using NDWI

\subsection{Multi-band Spectral Correlation Threshold Method (MSCT)}

According $(\mathrm{Xi}, 2009)$ to the different reflectance of water and shadow in the green band, red band, NIR band and MIR band, this paper using the logic relation shown in formula (2) to extract river.

$$
(T M 2+T M 3)-(T M 4+T M 5)>T 1
$$

$$
\begin{aligned}
& \text { where } \quad \text { TM2 }=\text { green band } \\
& \text { TM3 }=\text { red band } \\
& \text { TM4 }=\text { NIR band } \\
& \text { TM5 }=\text { MIR band } \\
& \text { T1 }=\text { threshold }
\end{aligned}
$$

Through several attempts, finally determined $\mathrm{T} 1$ is equal to 35 , which can minimize the wrong shadow and the leakage of tiny rivers. The result of river extraction using this method is shown in Figure 5.

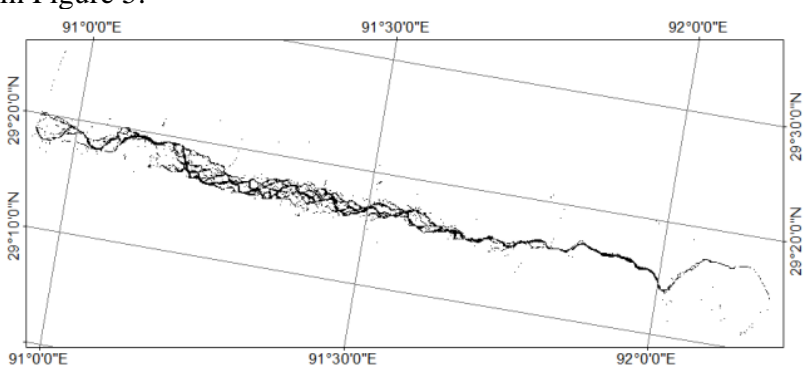

Figure 5. River extraction result using MSTC

\subsection{Maximum Likelihood Classification Method (MLC)}

MLC (Yang, 2008) is a nonlinear classification based on the Bias criterion. Compared with other supervised classification methods, this method has the least misclassification probability, is a relatively mature supervised classification method. Based on the false colour composite image shown in Figure 3, using MLC to extract river after selecting training samples, the result is shown in Figure 6. 


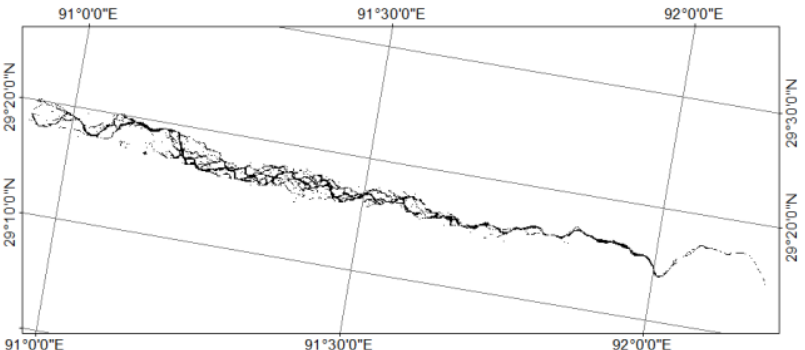

Figure 6. River extraction result using MLC

\subsection{Object-oriented Classification Method (OC)}

In order to make better use of the rich texture information of high resolution images and improve the classification accuracy, $\mathrm{OC}$ emerges as the times require. However, the OC based on medium resolution image is less at present, so this paper used this method to extract river based on ETM+ images in order to analysis the applicability of this method to medium resolution image.

The (Guan, 2010) process of OC is divided into two steps: image segmentation and classifier construction. The result of river extraction using this method is shown in Figure 7.

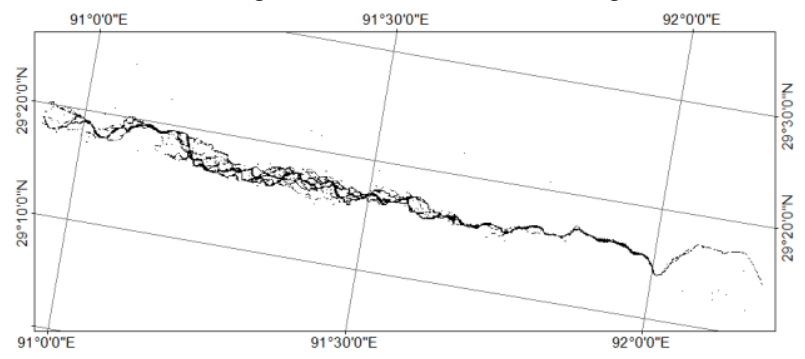

Figure 7. River extraction result using OC

\subsection{Accuracy Analysis}

From Figure 8 we can see clearly that there are two types of error in the river extraction processing, the area marked with red box in Figure $a$ is missing river, and in Figure $b$ is shadow. Therefore, two indexes are defined: the correct rate $(\mathrm{C})$ and the error rejection rate (E). The $\mathrm{C}$ indirectly reflects the error caused by the missing river area, and the $\mathrm{E}$ directly reflects the error raised by the extraction of the shadow as a river. These two indicators are calculated as follows:

$$
C=\frac{S_{3}}{S_{2}} * 100 \% \quad E=\frac{S_{1}-S_{3}}{S_{2}} * 100 \%
$$

where $\quad S_{1}=$ river area extracted by each method

$\mathrm{S}_{2}=$ river area extracted manually

$\mathrm{S}_{3}=$ overlap river area

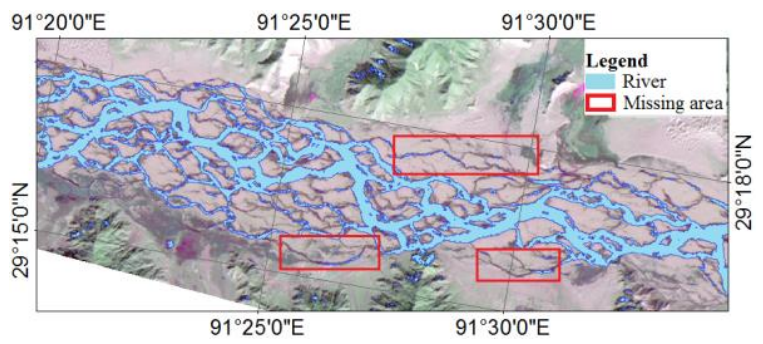

(a)

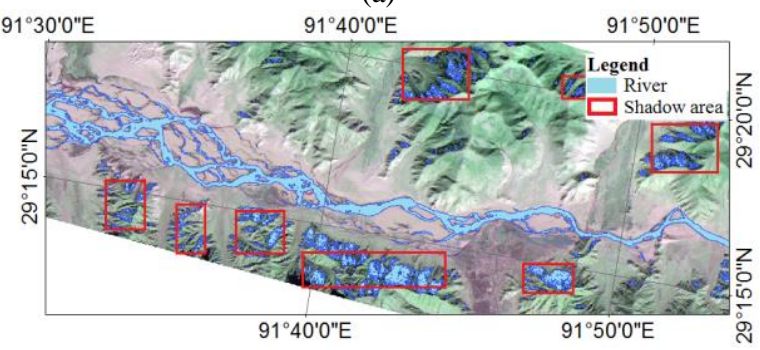

(b)

Figure 8. Error types in river extraction process (a) Missing river area (b) Wrong shadow area

In order to analyse the accuracy of different methods quantitatively and determine the optimal one, we extracted Yarlung Zangbo River manually based on true color image map using ArcGIS, and took it as the standard, the river area as the index, analysed the accuracy of various methods of river extraction, the results shown in Table 2.

\begin{tabular}{|c|c|c|c|c|}
\hline $\begin{array}{c}\text { River extraction } \\
\text { methods }\end{array}$ & $\begin{array}{c}\text { Total area } \\
\left(\mathrm{km}^{2}\right)\end{array}$ & $\begin{array}{c}\text { Overlap } \\
\text { area }\left(\mathrm{km}^{2}\right)\end{array}$ & $\mathrm{C}$ & $\mathrm{E}$ \\
\hline NDWI & 136.76 & 84.23 & $90.1 \%$ & $62.4 \%$ \\
MSTC & 104.5 & 87.31 & $93.3 \%$ & $20.2 \%$ \\
MLC & 84.50 & 78.89 & $84.3 \%$ & $7.1 \%$ \\
OC & 94.61 & 84.79 & $90.6 \%$ & $11.6 \%$ \\
Manually & 93.53 & 93.53 & $100 \%$ & $0 \%$ \\
\hline
\end{tabular}

Table 2. Accuracy of different river extraction methods

Table 2 shows that the $\mathrm{C}$ of NDWI is relatively high, but its $\mathrm{E}$ is the highest among these methods because it cannot divide rivers and shadows very well, in other words, NDWI is one of the weakest ways to eliminate shadows. The C of MSTC for river extraction is as high as $93.3 \%$, is the highest among several methods, but the ability to eliminate shadows is not particularly satisfactory, and its E is still above $20 \%$. The MLC has the least E, although it has the best ability to eliminate shadows, but its $\mathrm{C}$ is the lowest, which means the extraction of river information is incomplete and the missing area is too large. The $\mathrm{C}$ of OC is only slightly lower than that of MSTC, the effect of extracting river is relatively good, and its $\mathrm{E}$ is slightly higher than that of MLC method, the ability to eliminate shadows is also strong.

In summary, considering the two factors of shadow culling ability and river extraction ability, OC is the best method to extract river, MSTC as a band operation method with advantages of simple operation and fast processing speed has good effect in river extraction, while NDWI and MLC is less effective in river extraction compared with the previous two methods. 


\section{ANALYSIS OF YARLUNG ZANGBO RIVER CHANGE}

\subsection{River Information Extraction}

Extract information of upstream and midstream of Yarlung Zangbo River from Landsat images which are obtained in different periods. Each image needs to be preprocessed before river information extraction, including radiometric correction, band fusion and image cutting. Then, OC is used to extract Yarlung Zangbo River from four images.

As described in section 2.4, OC could not completely eliminate the shadow area, in order to reduce the impact of river extraction error when analysing river change, we need to use ArcGIS to do some modification on the extraction results. After removing a small fraction of the shadow and non-water area of Yarlung Zangbo River, the results of Yarlung Zangbo River extravtion are shown from Figure 9 to Figure 12.

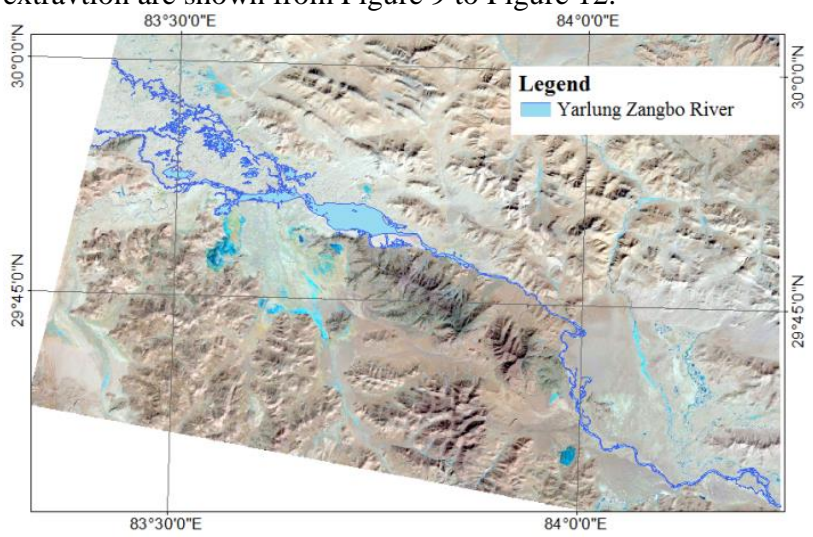

Figure 9. Extraction result of upstream in 2002

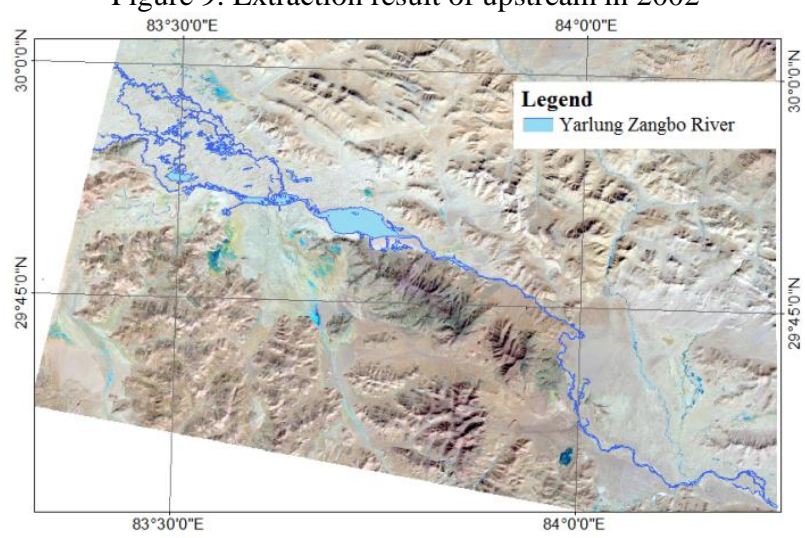

Figure 10. Extraction result of upstream in 2016

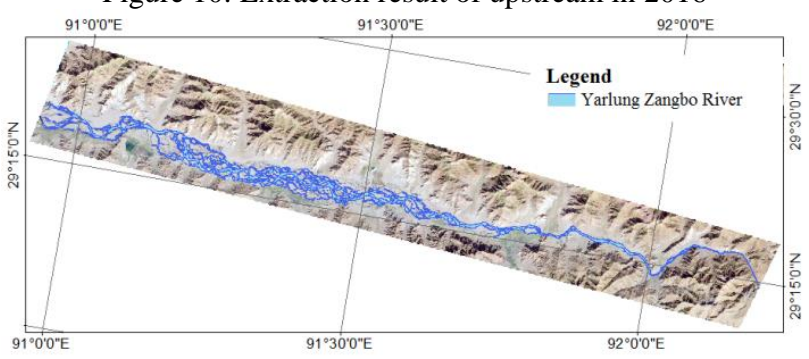

Figure 11. Extraction result of midstream in 2000

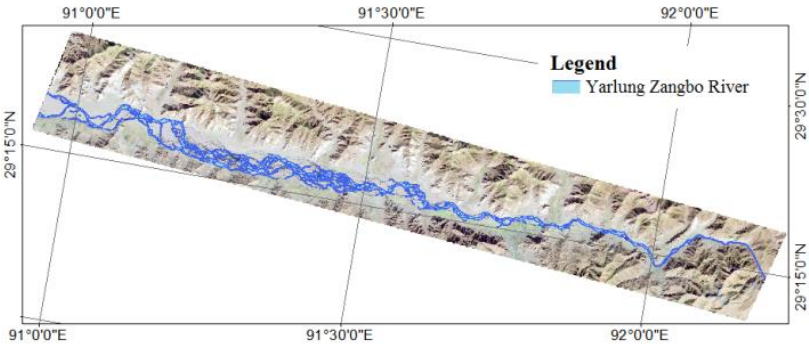

Figure 12. Extraction result of midstream in 2015

\subsection{River Change Analysis}

As one of the main rivers in the southwest river source area, analysing the spatial distribution and river change of Yarlung Zangbo River can provide a theoretical basis and data support for the use and protection of water resources, the economic development of Yarlung Zangbo River basin, and government decision-making.

In order to observe the river changes better, the river extraction results of upstream and midstream from two different period images are superimposed respectively using ArcGIS. Stacking results are shown in Figure 13 and Figure 14. At the same time, the area of Yarlung Zangbo River in each image is calculated to quantitatively analyse the change of the river, and the results are shown in Table 3.
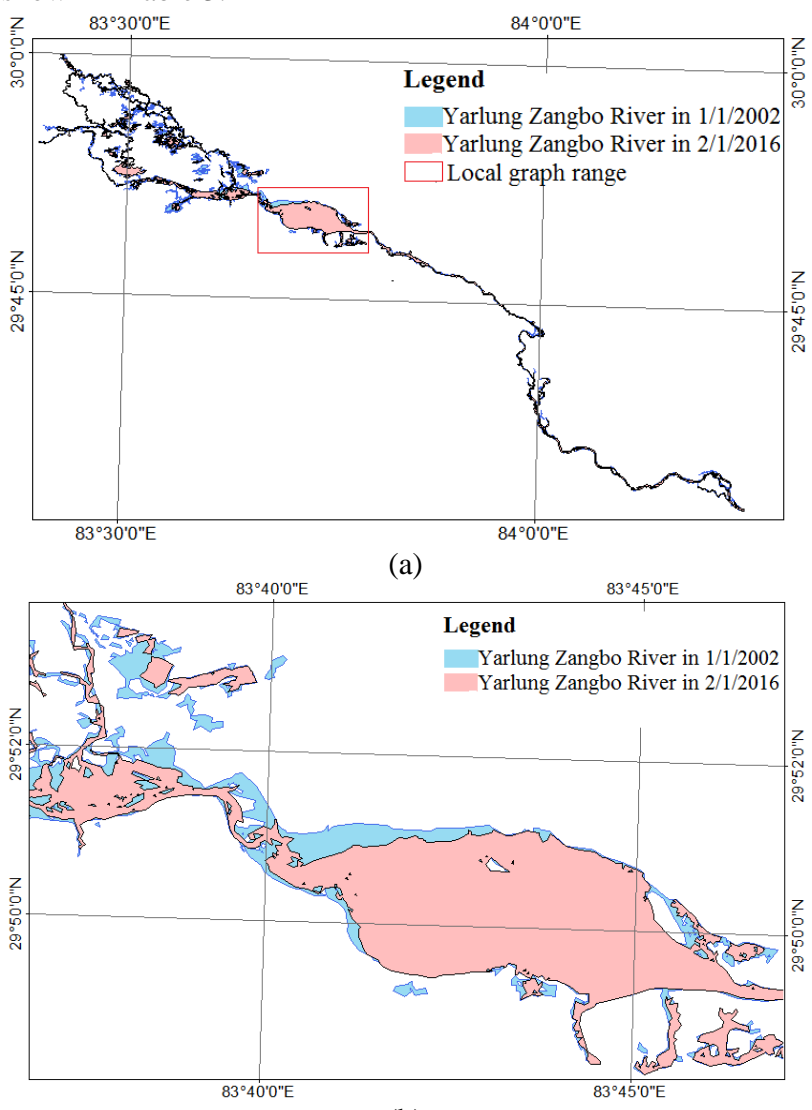

(b)

Figure 13. Superimposed river extraction results of upstream of Yarlung Zangbo River in two periods (a) Whole graph (b) Local graph 


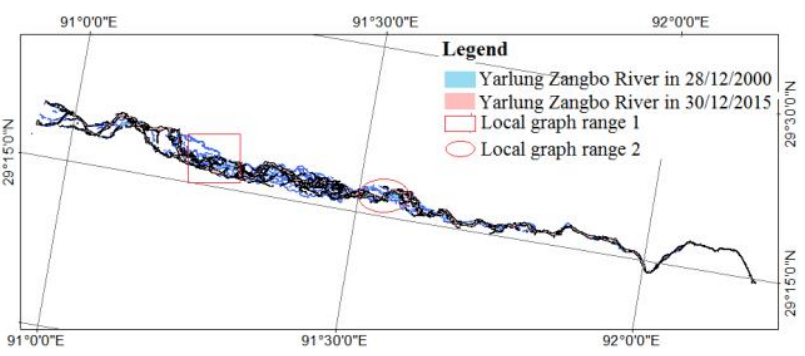

(a)

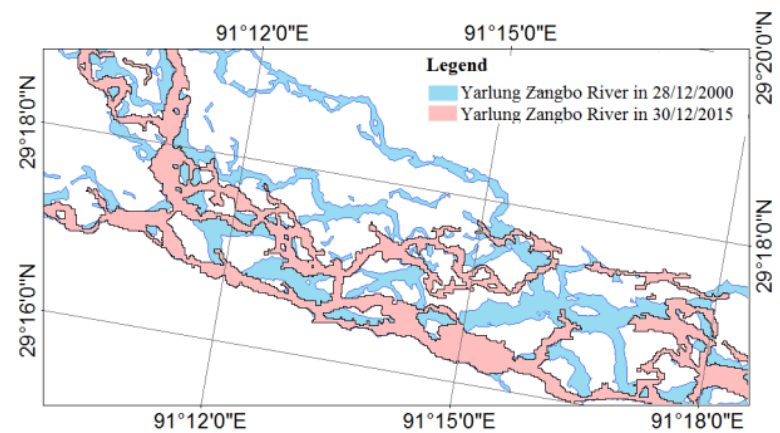

(b)

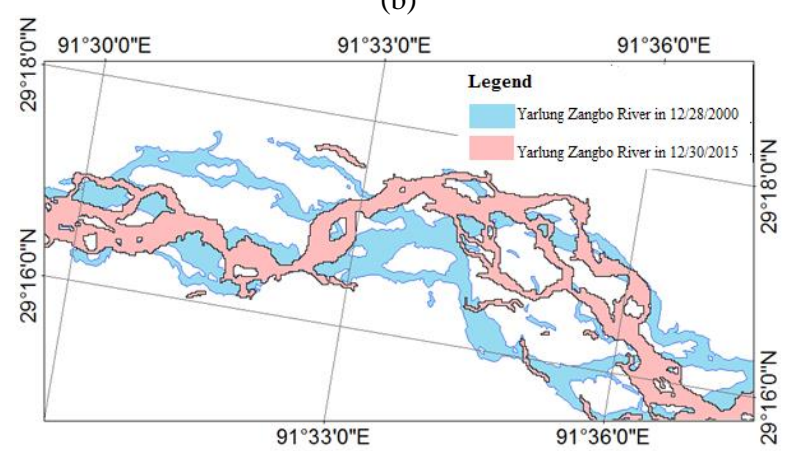

(c)

Figure 14. Superimposed river extraction results of midstream of Yarlung Zangbo River in two periods (a) Whole graph (b) Local graph 1 (c) Local graph 2

\begin{tabular}{|c|c|c|c|c|}
\hline $\begin{array}{c}\text { Yarlung } \\
\begin{array}{c}\text { Zangbo } \\
\text { River }\end{array}\end{array}$ & $\begin{array}{c}\text { River area } \\
\text { in } \\
\begin{array}{c}2000 / 2002 \\
\left(\mathrm{~km}^{2}\right)\end{array}\end{array}$ & $\begin{array}{c}\text { River area } \\
\text { in } \\
2015 / 2016 \\
\left(\mathrm{~km}^{2}\right)\end{array}$ & $\begin{array}{c}\text { Change } \\
\text { area } \\
\left(\mathrm{km}^{2}\right)\end{array}$ & $\begin{array}{c}\text { Change } \\
\text { rate }\end{array}$ \\
\hline Upstream & 76.22 & 61.25 & -14.97 & $-19.6 \%$ \\
Midstream & 92.367 & 78.05 & -14.32 & $-15.5 \%$ \\
\hline
\end{tabular}

Table 3. River area of upstream and midstream of Yarlung Zangbo River in different year

As we can see from Figure 13 and 14, both the upstream and midstream of Yarlung Zangbo River have a substantial reduction in the river area, and it can be found the extent of reduction is similar from Table 3. But the upstream change rate is slightly larger, reaching $-19.6 \%$. In addition, Figure 14 shows that the change of some watercourse in midstream of Yarlung Zangbo River is relatively large, and there are phenomenon of river diversion and river disappearance, which may be the result of natural or artificial transformation.

\section{CONCLUSION}

OC can make full use of the rich information of texture and spatial features contained in remote sensing images, and it is the best way to extract river information. MSTC can extract river information more completely, but it will have more shadow at the same time, which will affect the extraction accuracy. MLC is relatively weak in river extraction because it can only be classified by spectral information. NDWI cannot solve the problem of shadow misunderstanding, its effect of extracting river is relatively poor.

The river area of upstream and midstream of Yarlung Zangbo River shows a decreasing trend as a whole, and there are phenomenon of river diversion and river disappearance in midstream.

Studying river extraction in area which has remote location and complex terrain based on satellite remote sensing images has great advantages. Using remote sensing image processing technology can extract river information accurately and efficiently, and it can well monitor river change combining with geographic information technology.

\section{ACKNOWLEDGEMENTS}

This research was supported by the National Science Foundation of China (91547210, 41771471, 41201425), the National Key Research and Development Program of China (2017YFA0603102), and the Fundamental Research Funds for the Central Universities.

\section{REFERENCES}

Guan, Z., 2010. Research on object-oriented remote sensing image classification. Science and Technology Innovation Herald, 34, pp. 8-10.

Lv, Y., 2014. Spatio-temporal variation in NDVI in the Yarlung Zangbo River basin and its relationship with precipitation and elevation. Resources Science, 36(3), pp. 603-611.

McFeeters, S. K., 1996. The use of the normalized difference water index (NDWI) in the delineation of open water features. International Journal of Remote Sensing, 17(7), pp. $1425-1432$.

Xi, X., 2009. Research of automatic extraction of water bodies on ETM+ images. Computer Engineering and Design, 30(4), pp. 993-996.

Yang, X., 2008. An elementary introduction to supervised and unsupervised classification of remote sensing image. Journal of Sichuan Geology, 28(3), pp. 251-254. 